\title{
A New Species of Eremias (Sauria: Lacertidae) from Highlands of Kermanshah Province, Western Iran
}

\author{
NASRULlAH RASTEGAR-POUYANI ${ }^{1}$ AND ESKANDAR RASTEGAR-POUYANI ${ }^{2}$
}

\author{
${ }^{I}$ Department of Biology, Faculty of Science, Razi University, Kermanshah, Iran.e-mail: nasrullah@ razi.ac.ir. \\ ${ }^{2}$ Department of Biology, Faculty of Science, Sabzevar University, Sabzevar, Iran.
}

Abstract.- A new and distinctive species of the genus and subgenus Eremias is described from the highlands of Kermanshah Province, western Iran at about $1800 \mathrm{~m}$ elevation. It is easily distinguished from all other species of the typical subgenus (E. velox, E. persica, E. strauchi, E. nigrolateralis, E. lalezharica, E. afghanistanica, E. regeli, E. suphani, and E. nikolskii) by a variable number of postmentals (4-5 pairs), smaller size, and distinctive color pattern. Furthermore, it can be distinguished by having a combination of characters against any of the species in the typical subgenus. Systematics of the genus and subgenus Eremias is shortly discussed.

Key words.- Lacertidae, Eremias, Eremias (Eremias) montanus, Western Iran, Zagros Mountains, Kermanshah province, Siah-Darreh

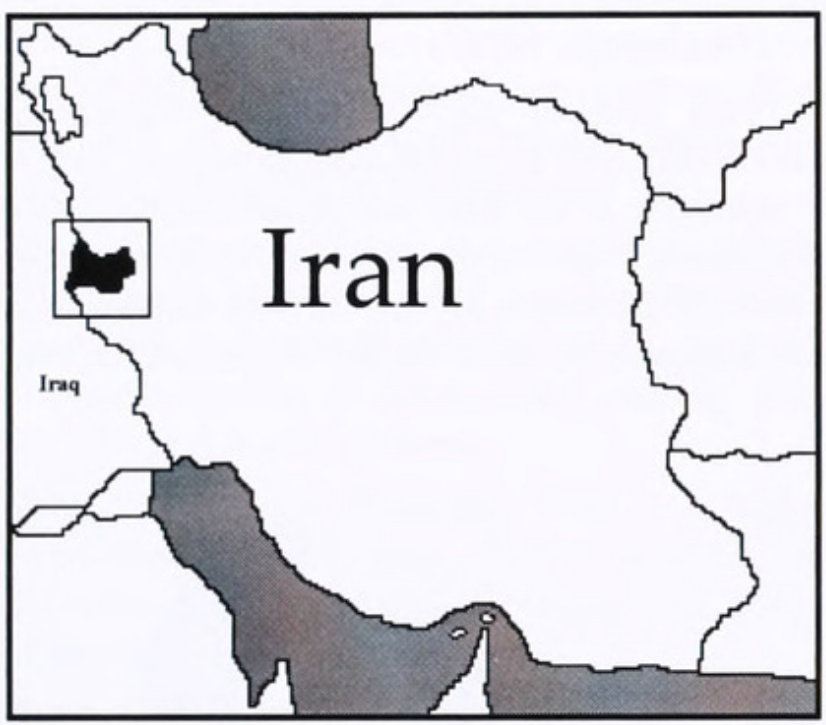

Figure 1. Location of Kermanshah province on the Iranian Plateau.

\section{Introduction}

The lacertid genus Eremias Fitzinger, 1834 encompasses about 33 species of mostly sand, steppe, and desert dweller lizards which are distributed from northern China, Mongolia, Korea, Central and southwest Asia to southeastern Europe (Rastegar-Pouyani and Nilson, 1997). The genus is Central Asian in its relationships and affinities (Szczerbak, 1974). About 15 species of the genus Eremias occur on the Iranian Plateau mostly in northern, central, and eastern regions (Rastegar-Pouyani and Nilson, 1997; Anderson, 1999). To date, no comprehensive study has been carried out on Eremias fauna of the Iranian Plateau and the systematic status of most taxa is in great need of a revisionary work. Szczerbak (1974), however,

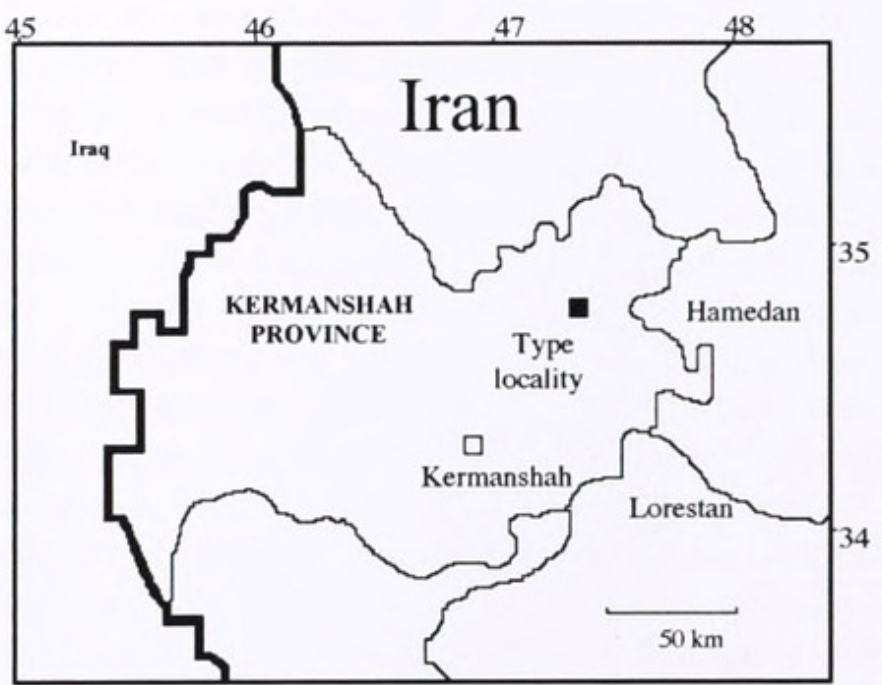

Figure 2. The type locality of Eremias (Eremias) montanus, vicinity of the Village of Siah-Darreh, about $60 \mathrm{~km}$ northeast of the city of Kermanshah, Kermanshah Province, western Iran.

revised Eremias and divided it into two distinguished genera based on morphological characters: Mesalina Gray and Eremias Fitzinger (see under systematic discussion).

As the first record of Eremias, in this paper we describe and introduce a new species of this genus from the upland and mountainous regions of Kermanshah province, western Iran at about $1800 \mathrm{~m}$ elevation. This province is located on the western periphery of the Iranian Plateau (Fig. 1) and a major part of it is covered by the Zagros Mountains. The type locality of Eremias (Eremias) montanus (sp. nov.) is located in an upland area surrounded by the Zagros Mountains 
with steppe vegetation (e.g., Astragalus, Euphorbia, Zygophyllum), about $60 \mathrm{~km}$ northeast of city of Kermanshah, Kermanshah province, western Iran (Fig. 2).

\section{Eremias montanus, new species (Figs. 3-4)}

Holotype and type locality: An adult female, Field number P198, collected by the senior author on 14 August 1995 from the upland regions of the Zagros Mountains, $60 \mathrm{~km}$ northeast of city of Kermanshah ( $\left.47^{\circ} 5^{\prime} \mathrm{E}, 34^{\circ} 52^{\prime} \mathrm{N}\right)$, Kermanshah Province, western Iran , at about $1800 \mathrm{~m}$ elevation

Paratypes: Two adult females, Field number P199P200, other information as for the holotype.

Diagnosis and comparison: A small-sized lacertid, maximum snout-vent length $(\mathrm{SVL})=57.2 \mathrm{~mm}$, tail length $=95 \mathrm{~mm}$, with 13-14 longitudinal and 27-28 transverse rows of ventral plates, slightly converging posteriorly; with 63-67 small, granular scales across

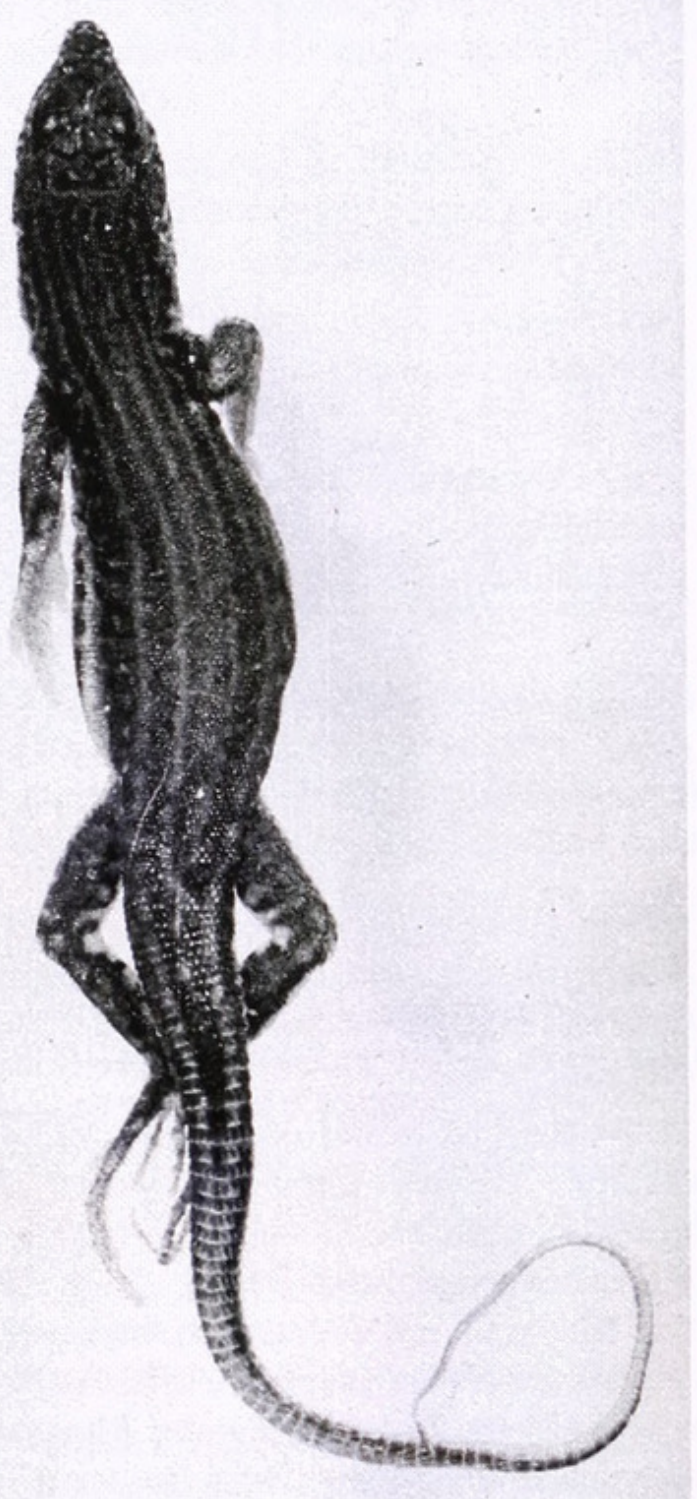

Figure 3. Eremias (Eremias) montanus holotype. middle of dorsum. A species belonging to the subgenus Eremias: subocular reaches mouth edge; one frontonasal; two supraoculars which are not completely separated from frontal and frontoparietals; distance between the femoral pores being narrow; color pattern "striped"; inhabitant of steppe and mountain-steppe landscapes (Szczerbak, 1974: 83).

On the other hand, it differs from all other species of its relevant subgenus based on having several distinguishing characters; the color pattern is distinctive and it is distinguishable from all other species in this character i. e., dorsum uniformly dark-brown without spots and ocelli, interrupted by five light longitudinal stripes; the vertebral stripe bifurcating on the nape, two paravertebrals on each side; a broad dorso-lateral stripe containing one or two regularly arranged light spots (different from the other Eremias species in this character); Furthermore, it differs from each species of the typical subgenus in the following character combinations (Bischoff and Bohme, 1980; Bohme and Szczerbak, 1991; Rastegar-Pouyani and Nilson, 1997; Szczerbak, 1974) :

From Eremias nigrolateralis Rastegar-Pouyani and Nilson, 1997 in having a much smaller size, lack of separation of the third pair of submaxillary shields by granular scales ( $0 \%$ versus $100 \%)$, lower count of gulars (23-24 versus 41-42), variable number of submaxillary shields (33\% versus $0 \%)$, reach of femoral

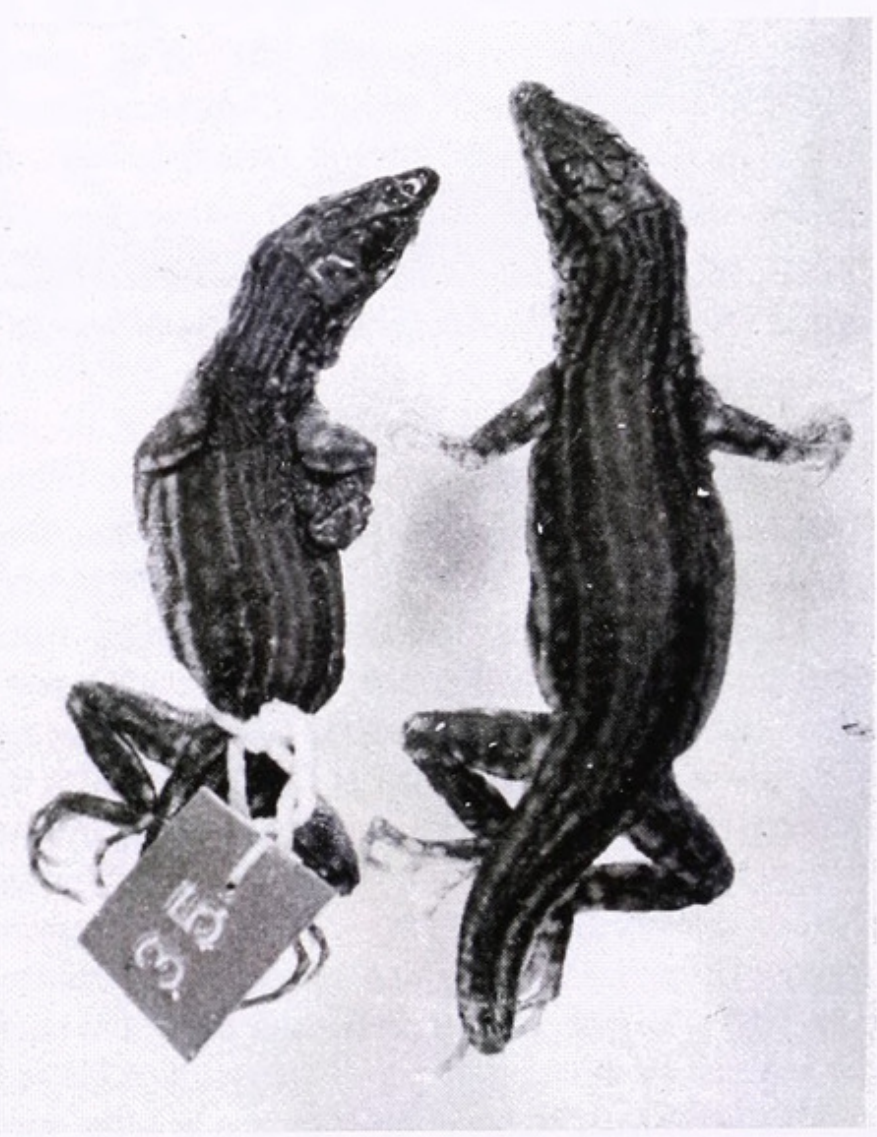

Figure 4. Eremias (Eremias) montanus paratypes. 
pores to the knee ( $100 \%$ versus $0 \%)$, and distinct differences in color pattern.

From Eremias persica Blanford, 1874 in having a smaller size, lower count of gulars (23-24 versus 2838 ), the absence of distinctly keeled upper caudal scales $(100 \%$ versus $75 \%)$, variable number of submaxillary shields ( $33 \%$ versus $4 \%$ ) and distinct differences in color pattern.

From E. velox (Pallas, 1771) in having a smaller size, in the absence of distinctly keeled upper caudal scales $(100 \%$ versus $0 \%)$, variable number of submaxillary shields ( $33 \%$ versus $5 \%$ ) and in color pattern.

From E. strauchi Kessler, 1878 in having a smaller size, the absence of distinctly keeled upper caudal scales $(100 \%$ versus almost $0 \%)$, variable number of submaxillary shields (33\% versus $9 \%$ ) and in color pattern.

From E. lalezharica Moravec, 1994 in having variable number of submaxillary shields (33\% versus $0 \%$ ), higher count of dorsals (63-68 versus 54-59), no contact of gulars with the second pair of submaxillary shields, lack of a small scale between prefrontals, and distinct differences in color pattern.

From E. afghanistanica Bohme and Szczerbak, 1991 in a much higher count of dorsal scales (63-68 versus 44-46), lower count of gulars (23-24 versus 2528 ), variable number of submaxillary shields $(33 \%$ versus $0 \%$ ), and in color pattern.

From E. nikolskii Bedriaga, 1905 in a higher count of dorsals (63-68 versus 45-59), variable number of submaxillary shields ( $33 \%$ versus $8 \%$ ), and in color pattern.

From E. regeli Bedriaga, 1905 in a higher count of dorsals (63-68 versus 43-61), higher number of scales in the 9th-10th caudal annulus (27-28 versus 17-25), the absence of distinctly keeled upper caudal scales $(100 \%$ versus $0 \%)$, variable number of submaxillary shields (33\% versus 3\%), and in color pattern.

Description of holotype: An adult female, preserved in $75 \%$ ethyl alcohol in good condition; body small and moderately depressed; a species of the subgenus Eremias (Szczerbak, 1974:83); five pairs of submaxillary shields, first three pairs in contact, the fourth and fifth pairs widely separated; first pair of submaxillary shileds as large as the fifth and in contact with mental anteriorly, with first and second infralabials laterally; the fifth sabmaxillary pair each in contact with the fourth pair anteriorly, being surrounded by 8 granular scales laterally and posteriorly; 7-8 supralabials, 4-5 of which anterior to subocular which borders the mouth; two large nasals in contact with rostral anteriorly, with first and second supralabials laterally, and with frontonasal and first loreal posteriorly, the former being single, broader than long and laterally in contact with first loreal and posteriorly with prefrontals; two prefrontals each smaller than frontonasal and almost as long as broad and laterally in contact with second loreal and posteriorly with frontal and granules of supraocular region; only frontonasal with distinct concavity; frontal almost as long as prefrontal and frontonasal together, broadened and posteriorly and laterally partly in contact with supraoculars (and partly separated from the latter by 2-3 large scales, not by granules) and posteriorly with frontoparietals; two frontopariatals almost as large as a single supraocular, laterally being in contact with the second supraocular, and posteriorly with interparietal and parietals, the former being small and relatively lozenge-shaped, surrounded by frontoparietals and parietals; two vey large and plate-like parietals, almost as long as broad, being in contact behind interparietal; a vestigial occipital; two loreals, first one small, surrounded by first two supralabials, nasal, frontonasal, and the second loreal which is distinctly large with an evident keel; 6-6 supraciliaries, separated from supraocular by a series of 42-44 granules; postocular elongate, surrounded by granules anteriorly; temporal regionmostly covered by granular scales becoming large towards the orbit, more than 100 on each side; tympanic scale distinct and elongated obliquely, almost the same size on both sides; tympanum vertically elongated, slightly larger than orbit; no distinct supratemporal; subocular huge, broader than long with a distinct ridge being extensively in contact with the lower edge of orbit; lower eyelids with a semitranslucent membrane made up of about 22 enlarged scales; collar well pronounced, not serratted, made up of 10 scales, the two medial ones the largest; gular fold weakly developed, 23-24 gulars from symphysis of chin shields to median gular, becoming enlarged posteriorly; 13-14 longitudinal and 27-28 transverse rows of almost squarish ventral plates from collar to hindlimbs; anterior series of ventrals to some extent irregular, median ventral longer than broad; dorsal scales juxtaposed, smooth, granular, becoming slighly larger posteriorly, 63-68 scales across the middle of dorsum, and about 160-164 scales in a single row from occiput to a point just above the vent; proximal caudals larger than posterior dorsals but the change being gradual; caudals becoming large, elongate, and slightly keeled distally, arranged in distinct whorls, 27-28 scales in the 10th whorl behind the vent; upper forearm covered dorsally by enlarged, juxtaposed, and almost lozenge-shaped scales; lower forearm covered 
with granules; upper hindlimbs covered externally by granules, externally by large shields; tibia covered dorsally by slightly pointed granules, ventrally by large plates which are slightly keeled, two plates in a transverse row; no fringes on the toes, 18-20 uni-and bi-carinate lamellae under fourth toe, proximal part of lower fourth toe containing two complete rows of lamellae, distal part with a single row (in this character it is quite different from all other species of its relevant subgenus); 18-19 femoral pores in each side, the two series separated anteriorly by a narrow space consisting of three scales; preanal region encompassing 24 large shields, the four median ones being the largest; 6 plates in longitudinal row from the space between femoral pores to anterior edge of the vent.

Coloration and color pattern: Dorsum uniformly dark-brown without spots and ocelli, interrupted by five light, narrow longitudinal stripes: one vertebral bifurcating on the nape, two paravertebrals on each side; a broad dorso-lateral stripe containing one or two regularly arranged light spots; a ventro-lateral series of dark-brown spots, to some extent forming a stripe; upper surface of head uniformly olivish-brown; temporal and labial regions suffused by dark-brown; submaxillary region light-gray-cream; ventral region dirty white, suffused by bluish-brown; upper surface of limbs dark-brown containing numerous light spots; proximal upper surface of tail brown, distal part light brownish-gray; lower surfaces of limbs and tail yellowish-white.

Description of paratypes: The paratypes, two adult specimens, one male (P199) and one female (P200) approximate the holotype in almost all pertinent details. However, there are some minor differences between paratypes and the holotype as follows:

Male paratype: five submaxillary shields on the right side but only four on the left, the fifth vestigial; 13-14 longitudinal and 30-31 transverse ventral plates; 10 11 collars, 3-4 median ones the largest; 23-24 gulars in a longitudinal row from chin shields to collar; 2020 femoral pores, separated by three small scales; 23 24 lamellae under fourth toe; 23-27 scales around 10th tail annulus; 8-9 labials, 5 of them anterior to subocular; 6-6 lower labials; lower nasal resting on the first two supralabials; temporal scale vestigial; 6263 scales around widest part of dorsum; 162-167 scales in a single longitudinal row from occiput to vent.

Measurements $(\mathbf{m m}): \mathrm{SVL}=58.5 ; \mathrm{TL}=$ incomplete; Forelimb $=24$; Hindlimb $=39 ; \mathrm{HL}=15.5$.

Female paratype: only four pairs of submaxillary shield, the fifth vestigial; 15-17 longitudinal and 31-
33 transverse rows of ventral plates; 9 collars, 4-5 median ones the largest; $24-25$ gulars in a single longitudinal row from chin shields to collar; 20-20 femoral pores, separated by a space corresponding to two scales; $25-26$ scales on the 10th tail annulus, 24-25 subdigital lamellae under fourth toe; 8-9 supra- and 46 infralabials; temporal scales relatively small; frontal separated from the first supraocular by two large scales (not by granules); 65-67 scales around widest part of dorsum; 163-167 scales in a single longitudinal row from occiput to vent.

Measurements $(\mathbf{m m}): \mathrm{SVL}=52.9 ; \mathrm{TL}=$ incomplete; Forelimb $=23$; Hindlimb $=35.5 ; \mathrm{HL}=13.6$.

In color pattern they are quite similar to the holotype.

Habitat: During field work on the western regions of the Iranian Plateau in 1995, we surveyed the Zagros Mountains and the nearby mountain steppes in the northern parts of Kermanshah province. $60 \mathrm{~km}$ northeast of Kermanshah city, in the highland steppes, in vicinity of the Village of Siah-Darreh in an area named Sarpal, we came across to three specimens of a new taxon of the genus Eremias, described here as a new species. The habitat, which is surrounded by the Zagros Mountains, is characterized by a mountainsteppe; the vegetation is luxuriant steppe association: mainly Astragalus, Euphorbia, Artemisia, and Amigdalus as well as various species of the families Graminaceae and Compositeae (Fig. 5).

Since it is a mountainous region with relatively high elevation, the winter being harsh and cold, the summer being mild and rather short. All the specimens were foraging around the shrubs probably looking for prey. They were quite shy and wary and very difficult to capture. When alarmed, they took refuge under the shrubs or inside the underground holes. One of the most effective anti-predatory adaptations evolved in these lizards is the ability to lose the tail (autotomy) when being touched by the predators (or collectors). Hence, we could only collect one specimen with a complete tail and the other specimens lost their tails during capturing.

In September 1998, we re-surveyed the type locality in order to find more specimens of this species but without success. Whether it being a relictual and rare species, confined only to the type locality, or being distributed over a wider area in the western margin of the Iranian Plateau is yet to be established.

With regard to the occurrence of Eremias montanus in the highlands of Kermanshah province, the Procter record of E. velox, as the westernmost record, from Kuretu (Iran-Iraq border) (Procter, 1921:252) should seriously be reconsidered. 


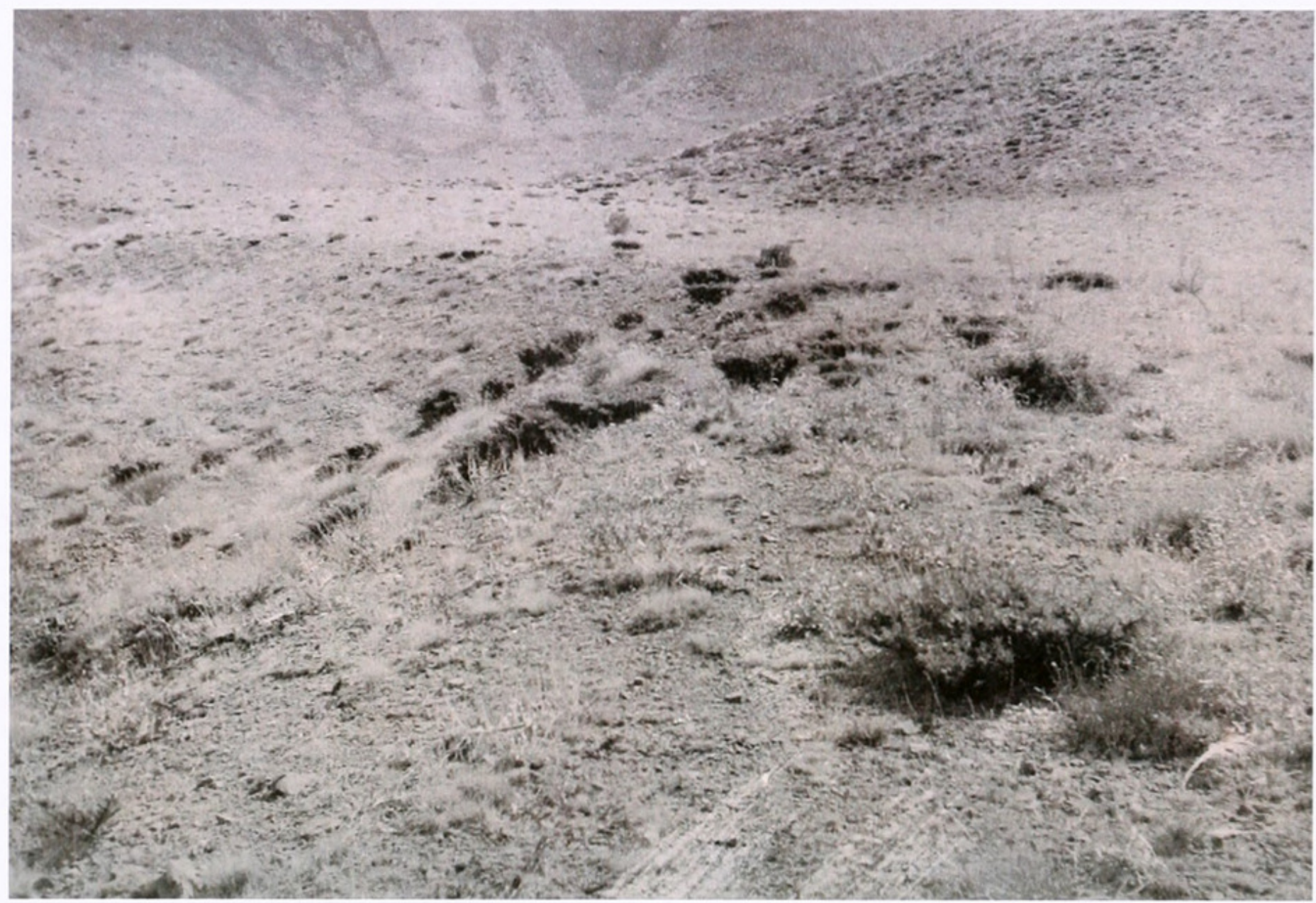

Figure 5. Habitat and type locality of Eremias (Eremias) montanus. $60 \mathrm{~km}$ northeast of Kermanshah, vicinity of Siah-Darreh village, Kermanshah Province, Western Iran.

Etymology: Eremias montanus is so named as it is apparently restricted in distribution to the upland and mountainous steppes of northeastern regions of Kermanshah province, western Iran.

Taxonomic account: As mentioned before, so far, the most complete work done on the complicated genus of Eremias (sensu lato) is of Szczerbak (1974) who studied almost all species and species complexes of this genus throughout the range. Based on morphological characters and geographic distribution, Szczerbak (1974) subdivided the inclusive genus Eremias (s. 1.) into two distinct genera; the genus Mesalina as a north African and lowland southwest Asian clade, and the genus Eremias (sensu stricto) which is mainly occurring in Central and northeast Asia. (Szczerbak, 1974).

Furthermore, Szczerbak (1974) subdivided Eremias (s.s) into five distinct subgenera: Eremias (Szczerbak, 1974: 83), Rhabderemias (Szczerbak, 1974: 201), Ommateremias (Szczerbak, 1974: 146), Pareremias (Szczerbak, 1974: 22-23), and Scapteria ( Szczerbak, 1974:247).

Except for the subgenus Pareremias, which is a Central and east Asian clade, all of the major species groups of the genus are presented on the Iranian Pla- teau (Anderson, 1999). Arnold (1986) who studied the hemipenes of lacertids supported the Szczerbak's subgeneric names. In a more recent study Arnold placed Eremias as the sister taxon of a clade including Acanthodactylus, Mesalina, and Ophisops-Cabrita (Arnold, 1989:238, 240 ). But Mayer and Benir (1994) have proposed a different scenario. According to these authors, Eremias is the sister taxon of Mesalina and both of them belong to a larger clade also containing Omanosaura and Ophisops. They believe that Eremias is not closely related to Acanthodactylus.

The Czech Biological Expedition to Iran in 1996 collected 8 specimens of an undetermined species of Eremias related to E. persica from the Zagros Mountains in Esfahan province at about 2000-2200 m elevation (Frynta et al., 1997: 9-10). Whether it is a new taxon or just a variety of E. persica is yet to be known.

Material examined: Eremias montanus $(\mathrm{n}=3)$ : $\mathrm{P}$ 198-200 (Field number), from around the Siah-Darreh Village (about $1800 \mathrm{~m}$ elevation), $60 \mathrm{~km}$ northeast city of Kermanshah, Kermanshah province, western Iran. 
Eremias nigrolateralis $(\mathrm{n}=2)$ : GNHM. Re. ex. 5147-5148, from $150 \mathrm{~km}$ northeast of Shiraz, Fars province, south-central Iran.

Eremias persica $(n=4)$ : GNHM. Re. ex. 51595162 , from $150 \mathrm{~km}$ northeast of Shiraz, Fars province, south-central Iran.

Eremias persica $(\mathrm{n}=28)$ : GNHM. Re. ex. 51635190, from $45 \mathrm{~km}$ east of Arak on the road to Qum, Markazi province, north-central Iran.

Eremias persica $(\mathrm{n}=4)$ : GNHM. Re. ex. 51915194, from $65 \mathrm{~km}$ west of Tehran, between EshtehardSaveh, Tehran province, northern Iran.

Eremias persica $(\mathrm{n}=2)$ : GNHM. Re. ex. 5195 5196, from $45 \mathrm{~km}$ east of Golpaygan, Esfahan province, central Iran.

Eremias persica $(\mathrm{n}=4)$ : GNHM. Re. ex. 5197 5200 , from $50 \mathrm{~km}$ north of Delijan on the road to Qum, Markazi province, north-central Iran.

Eremias persica $(\mathrm{n}=1)$ : GNHM. Re. ex. 5201, from $50 \mathrm{~km}$ north of Abadeh, Fars province, southcentral Iran.

Eremias persica $(\mathrm{n}=1)$ : GNHM. Re. ex. 5202, from $50 \mathrm{~km}$ east of Hamedan on the road to Qazvin, Hamedan province, western Iran.

Eremias persica $(\mathrm{n}=3)$ : GNHM. Re. ex. 52035205 , from $5 \mathrm{~km}$ west of Takestan on the road to Zanjan, Zanjan province, northwestern Iran.

Eremias velox $(\mathrm{n}=4)$ : GNHM. Re. ex. 5122(14), from around the Carin River, $250 \mathrm{~km}$ E-SE Almaty (Alma Ata), Kazakhstan.

Eremias velox $(\mathrm{n}=2)$ : GNHM. Re. ex. $5120(1$ 2), from Mulali Kurozek, eastern Kazakhstan.

Eremias velox $(\mathrm{n}=2)$ : GNHM. Re. ex. 5121(12), from the Taldi Korgau District, northeast Kazakhstan.

Eremias velox $(\mathrm{n}=2)$ : GNHM. GK. $18881(1-2)$, from Archenjan Village (1), and $30 \mathrm{~km}$ north of Mary (2), Turkmenistan.

Eremias strauchi $(\mathrm{n}=3)$ : GNHM. Re. ex. 4411 (1-3), from Golestan National Park, Mazandaran province, northeastern Iran.

Abbreviations : GNHM. Re. ex. = Gothenburg Natural History Museum, Reptilia exotica; GNHM. GK. = Gothenburg Natural History Museum, General Katalogue.

\section{Acknowledgements}

We wish to thank the Razi University authorities (Kermanshah-Iran) for their generous help and support during field work in western Iran.
We thank the Gothenburg Natural History Museum (Gothenburg-Sweden) for loan of Eremias specimens. Also we thank Dr. Michael Golubev for translation of the relevant Russian literature.

\section{Literature Cited}

Anderson, S. C. 1999. The Lizards of Iran. Society for the study of Amphibians and Reptiles 442 pp.

Arnold, E. N. 1986. The hemipenis of lacertid lizards (Sauria : Lacertidae): structure, variation and systematic implications. Journal of Natural History 20:12211257.

Arnold, E. N. 1989. Towards a phylogeny and biogeography of the Lacertidae : relationships within an Old-World family of lizards derived from morphology. Bulletin of the British Museum (Natural History), Zoology 55(2):209-257.

Bischoff, W. and W. Bohme. 1980. Der systematische Status der turkischen Wustenrenner des Subgenus Eremias (Sauria: Lacertidae). Bonner Zoolgische Beiträge, N. F. 26:297-306.

Bohme, W. and N. N. Szczerbak. 1991. Ein neuer Wustenrenner aus dem Hochland Afghanistans, Eremias (Eremias) afghanistanica sp. n. (Reptilia: Sauria : Lacertidae). Bonn. Zool. Beitr. 42:137-141.

Frynta, D., J. Moravec, J. Cihakova, J. Sadlo, Z. Hodkova, M. Kaften, P. Kodym, D. Kral, V. Pitule, and L. Sejna. 1997. Results of the Czech Biological Expedition to Iran. Part 1. Notes on the distribution of amphibians and reptiles Acta Societatis Zoologicae Bohemicae 61:3-17.

Mayer, W. and G. Benyr. 1994. Albumin-Evolution und Phylogenese in der Familie Lacertidae (Reptilia: Sauria). Annalen Naturhistorischen Museums in Wien 96B:621-648.

Moravec, J. 1994. A new lizard from Iran, Eremias (Eremias) lalezharica sp. n. (Reptilia: Lacertilia: Lacertidae). Bonner Zoolgische Beiträge 45(1):61-66.

Procter, J. B. 1921. Further lizards and snakes from Persia and Mesopotamia. Journal of the Bombay Natural History Society 28(1):251-253

Rastegar-Pouyani, N. and G. Nilson. 1997. A New Species of Eremias (Sauria: Lacertidae) from Fars Province, South-Central Iran. Russian Journal of Herpetology 4(2):94-101.

Szczerbak, N. N. 1974. Yashchurki Palearktiki (Palearctic species of Eremias ). Kiev. 295 pp. 


\section{$2 \mathrm{BHL}$ Biodiversity Heritage Library}

Rastegar-Pouyani, Nasrullah, Rastegar-Pouyani, Eskandar, and Rastegar-Pouyani, Eskandar. 2001. "A new species of Eremias (Sauria: Lacertidae) from highlands of Kermanshah Province, western Iran." Asiatic herpetological research 9, 107-112. https://doi.org/10.5962/bhl.part.15563.

View This Item Online: https://www.biodiversitylibrary.org/item/21131

DOI: https://doi.org/10.5962/bhl.part.15563

Permalink: https://www.biodiversitylibrary.org/partpdf/15563

\section{Holding Institution}

Harvard University, Museum of Comparative Zoology, Ernst Mayr Library

\section{Sponsored by}

Harvard University, Museum of Comparative Zoology, Ernst Mayr Library

\section{Copyright \& Reuse}

Copyright Status: In copyright. Digitized with the permission of the rights holder.

Rights Holder: Asiatic Herpetological Research Society \& Chengdu Institute of Biology, Chinese Academy of Science License: http://creativecommons.org/licenses/by-nc-sa/3.0/

Rights: https://biodiversitylibrary.org/permissions

This document was created from content at the Biodiversity Heritage Library, the world's largest open access digital library for biodiversity literature and archives. Visit BHL at https://www.biodiversitylibrary.org. 